\title{
Predictors of locoregional recurrence in T1- 2N0 tongue cancer patients
}

\author{
Souichi Yanamoto $\cdot$ Shin-ichi Yamada - Hidenori Takahashi • Goro \\ Kawasaki $\cdot$ Hisazumi Ikeda $\cdot$ Takeshi Shiraishi $\cdot$ Shuichi Fujita $\cdot$ Tohru \\ Ikeda $\cdot$ Izumi Asahina $\cdot$ Masahiro Umeda
}

S. Yanamoto (®) - S. Yamada • H. Takahashi • G. Kawasaki • M. Umeda

Department of Clinical Oral Oncology, Unit of Translational Medicine, Nagasaki University Graduate School of Biomedical Sciences, 1-7-1 Sakamoto, Nagasaki 852-8588, Japan

Phone: +81-95-819-7698, Fax: +81-9-819-7700

E-mail: syana@nagasaki-u.ac.jp

H. Ikeda • T. Shiraishi • I. Asahina

Department of Regenerative Oral Surgery, Unit of Translational Medicine, Nagasaki University Graduate School of Biomedical Sciences, 1-7-1 Sakamoto, Nagasaki 852-8588, Japan

S. Fujita $\cdot$ T. Ikeda

Department of Oral Pathology and Bone Metabolism, Unit of Basic Medical Sciences Nagasaki University Graduate School of Biomedical Sciences, 1-7-1 Sakamoto, Nagasaki 852-8588, Japan

Concise title: Locoregional recurrence in tongue cancer 


\begin{abstract}
Locoregional recurrence of oral tongue squamous cell carcinoma (OTSCC) has been considered a poor prognostic entity in terms of survival rate. The purpose of this study was to evaluate the incidence of locoregional recurrence and to identify significant risk factors for locoregional recurrence in early-stage OTSCC. We retrospectively reviewed the records of 58 patients who underwent radical surgery for T1-2N0 OTSCC. The local recurrence and regional recurrence rates were $10.3 \%$ (6/58 patients) and 15.5\% (9/58 patients) in this study, respectively. The survival rate of patients with local recurrence was $66.7 \%$, which was significantly lower than that (96.2\%) of patients without local recurrence, whereas the survival rates of patients with or without regional recurrence were not significantly difference. Pattern of invasion (POI), neoadjuvant chemotherapy (NAC) and the status of the surgical margin were identified as factors influencing local recurrence. In particular, the status of the deep surgical margin was a high potential independent risk factor. The deep surgical margin was resected closely in many NAC-treated cases, suggesting that NAC may lead to local recurrence and a poor outcome. No efficacy of NAC was observed, suggesting that the standard treatment for early OTSCC is surgery alone.
\end{abstract}

\title{
Keywords tongue cancer • recurrence • neoadjuvant chemotherapy • surgical margin
}

\footnotetext{
Abbreviations

OTSCC: oral tongue squamous cell carcinoma; POI: pattern of invasion; NAC: neoadjuvant chemotherapy; DOI: depth of invasion; LR: local recurrence; RR: regional recurrence; LRR: locoregional recurrence; DSS: disease specific survival; RFS: recurrence free survival; HR: harzard ratio; CI: confidence interval
} 


\section{Introduction}

Oral squamous cell carcinoma (OSCC) accounts for nearly 3\% of all cancer cases and is the sixth most common cancer in the world [1, 2]. The oral tongue is the most common site of OSCC. Oral tongue squamous cell carcinoma (OTSCC) is an aggressive cancer frequently associated with poor prognosis [1-3]. Five-year survival rates have remained essentially unchanged over the past 20 years despite advancements in treatment [3]. Treatment failure in OTSCC patients is most frequently due to local and regional recurrences $[4,5]$. The prognosis also depends or varies with nodal involvement, tumor thickness, and the status of the surgical margins [4-11]. In particular, the most significant prognostic factor in OTSCC is the presence of metastatic disease in the cervical lymph nodes [7, 9, 11]. Unfortunately, this metastatic disease is quite often subclinical or occult at the time of diagnosis and treatment; therefore, controversy exists regarding the treatment of the clinically negative neck in patients with T1-2N0 OTSCC. Surgery continues to be a well-established mode of initial definitive treatment for most patients with early stage OTSCC [12], and their survival rate is $65-85 \%$ [5, 7, 8, 13]. On the other hand, interstitial brachytherapy has been the accepted method of treatment for patients with early-stage OTSCC because of the high local control rate and preservation of shape and function of the tongue $[14,15]$. However, cervical lymph node metastases develop in some patients, even when the primary tumor has apparently been controlled. Moreover, radiotherapy raises certain problems, such as non-healing tongue ulcer, osteoradionecrosis of the mandible, radiation-induced secondary cancer [14-16]. For these reasons, our institution has discontinued interstitial brachytherapy for oral cancer. Patients with early-stage OTSCC treated with surgery are found to have a favorable prognosis compared with advanced cases; however, some early stage OTSCC patients have a poor prognosis.

The purpose of this study was to examine the incidence of recurrence in our department and to identify predictors of locoregional recurrence in patients with T1-2N0 OTSCC. This investigation may be helpful with the management of OTSCC patients undergoing radical surgery. 


\section{Materials and Methods}

\section{Patients}

We retrospectively reviewed the records of 58 patients who underwent radical surgery for T1-2N0 OTSCC between January 2001 and December 2010. The study cohort included patients with histologically confirmed diagnoses of OTSCC and a minimum follow-up of 12 months. All study patients underwent extensive pretreatment evaluations, including blood chemistry, complete blood cell count, chest X-ray, computed tomography (CT) and/or magnetic resonance imaging (MRI) of the head and neck area, thoracoabdominal CT, and provided informed consent to participate in the study. Data collected included demographic information, site, TNM stage at diagnosis, tumor histologic grade, pattern of tumor invasion, treatment, depth of tumor invasion, status of the margin, recurrence, and the adjuvant therapy used for disease control.

Tumor stage was classified according to the TNM classification of the International Union against Cancer [17]. Tumor histologic grade was defined according to the WHO classification [18]. Pattern of invasion (POI) was examined at the host/tumor interface. POI types 1 through 4 have been previously defined by Bryne et al. [19]. POI type 1 represents tumor invasion in a broad pushing manner with a smooth outline. POI type 2 represents tumor invasion with broad pushing "fingers" or separate large tumor islands, with a stellate appearance. POI type 3 represents invasive islands of tumor greater than 15 cells per island. POI type 4 represents invasive tumor islands smaller than 15 cells per island. This includes cord-like and single cell invasion. These evaluations were performed using biopsy specimens.

\section{Treatment and pathologic examination}

In our institute, the modality of surgery alone was preferred for the treatment of patients with oral cancer; however, patients who hesitated to consent to surgical intervention or for whom surgery was not available because of a busy schedule were selected for neoadjuvant chemotherapy (NAC). During the period of NAC, patients were encouraged to undergo surgery after completion of chemotherapy. 
All patients who received NAC underwent radical surgery. The regimen of NAC consisted of a combination of cisplatin-based multidrugs. In most patients, modifications of chemotherapy dosages were made for toxicity as indicated using standard criteria.

Primary tumors were excised with $\geq 1.5 \mathrm{~cm}$ safety margins (both superficial and deep margins). The extent of surgery was not modified according to the tumor response with NAC. All patients underwent partial glossectomy with curative intent. Elective neck dissection was not performed routinely in our institutions. Local recurrence was defined as lesions arising in the oral cavity relative to the primary tumor beyond 6 weeks within the first 5 years after the first definitive treatment. Recurrence arising at both the primary site and in the neck was also considered to be local recurrence. Recurrence arising only in the neck was defined as regional recurrence. Recurrence arising either at the primary site or in the neck was defined as locoregional recurrence. Patients with recurrences that were considered potentially curable and operable underwent salvage surgery and radiotherapy. Patients with recurrences that were considered incurable were treated with palliative chemotherapy.

For pathological examination of the invasion depth and surgical margin, all permanent section histological slides of primary resection specimens were reviewed retrospectively. Depth of invasion (DOI) was measured as the infiltrative portion of the tumor which extended below the surface of the adjacent mucosa. The keratin layer was not included in the measurements. Where the epithelium was destroyed (since the majority of the tumor showed ulceration), it was measured after reconstructing a virtual surface. Previous studies demonstrated that $\mathrm{DOI} \geq 4 \mathrm{~mm}$ had a predictive value for cervical lymph node metastasis in patients with T1-2N0 OTSCC; [20-24] therefore, in this study, DOI was classified as $\geq 4$ and $<4 \mathrm{~mm}$. Likewise, regarding the surgical margin, a large cohort study demonstrated that a pathological margin distance $\leq 4 \mathrm{~mm}$ was significantly associated with locoregional recurrence [25]; therefore, in this study, the status of the surgical margin was classified as $>4$ and $\leq 4 \mathrm{~mm}$ for the superficial and deep margins, respectively. All pathological assessments were performed by two expert pathologists (SF and TI) who were unaware of the clinical outcomes. 


\section{Statistical analysis}

The survival rate was calculated using the Kaplan-Meier method. Significance was evaluated using the log-rank test. Multiple regression study was performed using Cox proportional hazard analysis. Univariate and multivariate analyses were used to identify predictive factors for recurrence. Predictors that were not associated with both disease-specific survival (DSS) and recurrence-free survival (RFS) in univariate analysis were not included in multivariate analysis. Statistical analyses were performed using StatMate IV (Atms Co., Tokyo, Japan). In all analyses, $P<0.05$ was considered significant.

\section{Results}

\section{Patient characteristics and recurrence rate}

Patient demographic characteristics are summarized in Table 1. The male-tofemale ratio was 1.1 with 31 male subjects. The mean age at diagnosis was 65.1 years (range, 28-86 years). There were 27 (46.6\%) and 31 (53.4\%) patients with $\mathrm{T} 1$ and $\mathrm{T} 2$ disease, respectively. Fourteen (24.1\%) patients received NAC. In this study, only 3 (0.05\%) patients received postoperative radiotherapy. Postoperative radiotherapy with a dose field of $60 \mathrm{~Gy}$ was performed on patients with involved margins.

The local recurrence rate was $10.3 \%$ (6/58 patients) during the follow-up period. The mean follow-up period was 41.2 months for the whole series (range, 10-114 months). The mean period that had elapsed until local recurrence was 11.7 months (range, 2-24 months), with most local recurrences (5/6 patients, 83.3\%) occurring during the first year after treatment (100\% before 2 years). The regional recurrence rate (i.e., occult lymph node metastasis rate) was 15.5\% (9/58 patients) during the follow-up period. The mean period that had elapsed until regional recurrence was 7.4 months (range, 3-11 months), with all of the regional recurrences occurring during the first year after treatment. Taken together, the locoregional recurrence rate was $25.9 \%$ (15/58 patients) during the follow-up period. The mean period that elapsed until locoregional recurrence was 9.2 months (range, 2-24 months), with most locoregional recurrences (13/15 patients, $86.7 \%$ ) occurring during the first year after treatment (100\% before 2 years). 


\section{Clinical outcome and survival rate}

The 5-year DSS and RFS rate was 89.5\% and 73.3\%, respectively (Fig. 1). At the time of analysis, 6 patients developed local recurrence. Salvage surgery was performed in 5 of the 6 patients; radiation alone was performed in 1 patient with unresectable disease. The DSS rate for patients with local recurrence was $66.7 \%$ at 5 years postoperatively. The outcome in the local recurrence group was death due to primary lesion (2 patients) and death due to cervical metastasis (2 patients). Local control was impossible in 1 patient in whom a recurrent lesion was treated with radiotherapy, and this patient died from the primary lesion, showing that salvage surgery was performed in all 2 survivors, and the salvage rate was $40.0 \%$ (2/5 patients). The DSS rate for patients with no local recurrence was $96.2 \%$ at 5 years postoperatively. The outcome was death due to cervical and distant metastases, respectively.

\section{Univariate and multivariate analyses for recurrence and survival}

Univariate analysis (Table 2$)$ revealed that POI $(P=0.008)$, NAC $(P=0.039)$, the superficial margin $(P<0.001)$, the deep margin $(P=0.002)$, and perineural invasion ( $P=0.039$ ) were significantly associated with local recurrence. Gender, age, T-stage, histological grade, and DOI were not significantly associated with local recurrence. Regarding regional recurrence, no predictive factors were associated with occult lymph node metastasis. Histologic grade $(P<0.001)$, NAC ( $P=0.007)$, DOI $(P=0.024)$, the superficial margin $(P<0.001)$, the deep margin $(P=0.018)$, and perineural invasion $(P=0.044)$ were significantly associated with locoregional recurrence. The 5-year DSS rate was significantly associated with the following factors: POI $(P<0.001)$, NAC $(P<0.001)$, DOI $(P=0.013)$, the deep margin $(P=0.002)$, and perineural invasion $(P<0.001)$. The 5-year RFS rate was significantly associated with the following factors: histologic grade $(P$ $<0.001)$, POI $(P=0.010)$, NAC $(P=0.011)$, DOI $(P=0.026)$, the superficial margin $(P<0.001)$, and the deep margin $(P=0.037)$. Notably, POI, NAC, DOI and the deep margin were all significant predictive factors for the 5-year DSS and RFS rates. Local recurrence was also a significant prognostic factor for 5-year DSS ( $P=0.001$, Fig. 2); however, regional recurrence was not a significant prognostic factor for 5-year DSS ( $P=0.301$, Fig. 3). 
Multivariate analysis (Table 3 ) revealed that only the deep margin $(\mathrm{HR}=$ 14.83, $P=0.011)$ was an independent factor for local recurrence $(\mathrm{HR}=14.83, P=$ $0.039)$ and 5-year DSS (HR $=21.13, P=0.041)$ and RFS (HR $=7.15, P=0.007)$. In addition, POI was an independent prognostic factor for 5-year DSS.

\section{Effect of NAC, POI, and DOI on the deep margin status}

As mentioned above, the predictors associated with both DSS and RFS in univariate analysis were POI, NAC, DOI, and the deep surgical margin. In particular, multivariate logistic analysis revealed that a deep surgical margin status was an independent factor for local recurrence and survival. To examine the effect of POI, NAC, and POI on the deep margin status, we performed logistic regression analysis (predictor variable: POI, NAC, and DOI; response variable: deep margin status). POI and NAC were significantly associated with a deep surgical margin $(\mathrm{HR}=16.58 ; P=0.009$ and $\mathrm{HR}=13.34 ; P=0.002$, respectively) (Table 4).

\section{Discussion}

Locoregional recurrence in patients with OSCC remains a problem and can affect their survival [8, 26, 27]. In particular, regional recurrence is a high potential risk factor for survival in early-stage OTSCC. In our study of patients with T1-2N0 OTSCC, we observed 5-year DSS and RFS rates of $89.5 \%$ and $73.3 \%$, respectively. These outcomes compare very favorably with those reported in previous studies, which ranged from 67 to $86 \%$ [5, 13, 28]. Previous studies reported that local recurrence occurred in $9 \%$ to15\% [5, 13, 29-31]. In our study, the local recurrence rate of $10.3 \%$ was similar to those reported in the literature [5, 13, 29-31]. Some studies have demonstrated that pathological variables such as DOI, surgical margin, and POI could be reliable parameters for local recurrence in early-stage OTSCC [8-11, 20-31]. We observed that a higher incidence of local recurrence was associated with POI, NAC, closed surgical margin, and perineural invasion.

The relationship between POI and the incidence of local recurrence has been reported by some researchers $[6,8]$. Brandwein-Gensler et al. stated that the worst 
POI was associated with local recurrence, and this was because of the presence of tumor satellites with $1 \mathrm{~mm}$ or greater distance of intervening normal tissue at the tumor/host interface [8]. In this study, POI was identified as a significant predictive factor for local recurrence by univariate analysis but it was not an independent factor by multivariate analysis. There was a trend of increasing incidence of local recurrence with diffuse POI, but the number of patients with local recurrence was too small to find significant differences between local recurrence and POI. Although we did not examine the presence of tumor satellites at the tumor/host interface as stated by Brandwein-Gensler et al. [8], this evaluation may be useful for the further assessment of local tumor control. On the other hand, Spiro et al. reported that POI had a significant influence on survival, but not local recurrence [6]. Moreover, they concluded that patients with diffuse POI had a significant decrease in survival, presumably because they were more likely to be seen with nodal involvement [6]. The present study also indicated that POI was an independent prognostic factor for 5-year DSS, but not local recurrence. In addition, POI was not significantly associated with regional recurrence; the reason for this was unclear.

In the present study, we have demonstrated that NAC was a significant predictive factor for local recurrence. NAC, which is the use of systemic chemotherapy before definitive surgery and/or radiotherapy, has been an attractive approach in the management of head and neck squamous cell carcinoma (HNSCC). The benefits of NAC for patients with locally advanced HNSCC, as demonstrated by several clinical studies, include a reduction in distant metastasis, improved survival, and the preservation of organ function [31-35]; however, NAC has failed to demonstrate any significant improvement of survival in several randomized control trials $[32,34]$. On the other hand, some studies have also shown that patients whose disease responded to NAC had a better survival rate than those who received non-effective NAC [33, 36]. The efficacy of NAC is controversial, as described above, and no report supports NAC with a high evidence level. Accordingly, at present, the standard treatment of oral cancers is surgery alone, and radiotherapy or concomitant chemoradiotherapy after surgery is recommended for high-risk cases in which recurrence or metastasis is expected [12, 37, 38]. In our study, NAC increased the local recurrence rate over that in patients without NAC. An increase in the risk of local recurrence by NAC has not 
previously been reported but, in some studies on local recurrence, the local recurrence rate was higher in patients with NAC than in those without NAC, although the difference was not significant [37, 39]. Okura et al. demonstrated that NAC was associated with a significant increase in regional failure for patients with OSCC with N0 disease [37]. In this study, however, NAC was not associated with a significant increase in regional or locoregional recurrences, and it was unclear why NAC implied poor prognosis for patients with T1-2N0 OTSCC.

Several studies have demonstrated that DOI had a predictive value for cervical lymph node metastasis in patients with T1-2N0 OTSCC [20-24]; however, controversy exists about the optimal DOI cutoff point for a clinically relevant risk to cervical lymph node metastasis. Huang et al. determined the optimal DOI cutoff point of $\geq 4 \mathrm{~mm}$ by meta-analysis for prophylactic neck management [24]; therefore, in this study, DOI was classified $\geq \AA$ and $<4 \mathrm{~mm}$. Many previous studies have reported that DOI significantly predicted occult cervical metastases [20-24], and in our study, the regional recurrence rate was higher in patients with DOI $\geq 4 \mathrm{~mm}$ than in those with DOI $<4 \mathrm{~mm}$, although the statistical difference was not significant.

The results of this study showed that a deep surgical margin had a significant impact on local recurrence, DSS, and RFS, as seen in previous studies [6, 29, 3941]. Some studies have identified an association between the margin status and factors that impact outcome in oral cancer, including the $\mathrm{T}$ status, $\mathrm{N}$ status, DOI, and POI [6, 39, 41]. In this study, POI and NAC were significantly associated with a closed deep surgical margin. NAC and the deep surgical margin were apparently associated, suggesting that a deep margin is likely to be resected at a close site when NAC is applied. The superficial margin may have been more appropriately set than the deep margin because it was marked before NAC or set outside the unstained area of intraoperative Lugol's iodine staining, and this may have been the reason for the absence of an association with the superficial margin [42]. In contrast, the deep margin was set based on palpation during surgery or imaging diagnosis before NAC; therefore, we speculated that the most invasive front became unclear after modification by NAC, which may have resulted in resection with an insufficient safety margin. Moreover, we estimate that not only the mechanism for the closed margin but also the residual cancer cells after NAC is involved in the mode of local recurrence. Kim et al. suggested that these 
residual cancer cells after NAC possess the characteristics of cancer stem cell [43]. According to the cancer stem cell concept, NAC kills more cells in a tumor; however, it is believed to leave cancer stem cells behind, which might be an important mechanism in the development of resistance to NAC. Indeed, Bourhis et al. previously reported that NAC led to the selection of more aggressive cancer cells [44]. Further molecular biological examination is needed to demonstrate the involvement of cancer stem cell in local recurrence of NAC-treated cases. In NAC-treated early stage tongue cancer cases, the immune response may be debilitated during the postoperative wound healing period. Some authors reported that NAC significantly increased postoperative wound infection in HNSCC patients [45, 46]. Although, NAC may kill some residual tumor cells, but disadvantageously blocks the local defense of immune competent cells. This may also be a proposed mechanism for advantage of surgery alone over NAC administration.

Perineural invasion is a known predictor of survival, local recurrence, regional recurrence, and distant metastasis [8, 30, 47]. In the previous literature, the incidence of perineural invasion from head and neck SCC was reported to range from $6 \%$ to $30 \%$ [8, 47], similar to the $24.1 \%$ (14/58 patients) rate in the present study. Rahima et al. reported that perineural invasion was associated with DOI and regional recurrence [47]. In limited early-stage disease such as T1-2N0 OTSCC, perineural invasion may be small and low grade because of the superficial invasion. We found that perineural invasion was associated with local recurrence and 5-year DSS, but not regional recurrence by univariate analysis. In this study, perineural invasion should be considered a predictive factor that exhibits local aggressive behavior.

Tumor local recurrence implies a poor prognosis for patients with OSCC [26, 46-48]. The present study showed a 5-year DSS rate of $66.7 \%$ in patients with local recurrence. This outcome compares very favorably with those reported in previous studies, which ranged from 24.5 to $50.0 \%$ [26, 48-50]. Some studies reported that salvage surgery had a significantly improved survival time over that with radiation therapy and/or chemotherapy for local recurrent tumors [50, 51]. Ord et al. reported that salvage surgery for local recurrent tumors was performed in 54.2\% (13/24 patients), with a 52.6\% 3-year survival rate [51]. No patients receiving radiation therapy and/or chemotherapy for local recurrent tumors were 
salvaged $[49,50]$. In our study, salvage surgery was performed in $83.3 \%$ (5/6 patients), with a $66.7 \%$ 5-year survival rate and $40.0 \%$ salvage rate; therefore, our results support the use of salvage surgery as the best means of salvaging local recurrence, if the patient is resectable. Regional recurrence was the most common type of recurrence for early-stage OTSCC. Some researchers have reported occult cervical metastasis in an incidence ranging from $16 \%$ to $26 \%[7,11]$. The incidence of regional recurrence in our study was $15.5 \%$, comparable with other studies [7, 11]. In univariate analysis, only the histological grade was correlated with regional recurrence; however, only 5 patients had moderately or poorly differentiated SCC. Our results therefore did not support the modality that elective neck dissection should be indicated in patients with moderately or poorly differentiated SCC. As expected, once regional recurrence appears, prognosis is poor and there are few long-term survivors. Some previous studies showed that the salvage rate for patients with regional recurrence of early-stage OTSCC was extremely low, regardless of the size of the lesion, the status of the cervical nodes, and the treatment used for the recurrence $[52,53]$, whereas our study showed that salvage surgery was performed in $88.9 \%$ (8/9 patients) and 7 of the nine patients were salvageable, with a $77.8 \%$ salvage rate. Therefore, our results supported the use of salvage surgery as the best means of salvaging regional recurrence and did not indicate any advantage of elective neck dissection for the primary treatment of N0 neck in early OTSCC. This outcome compares very favorably with those reported in previous studies $[52,53]$. It seems that this outcome was due to our management of the regional area through early diagnosis and adequate salvage surgery.

In conclusion, the local recurrence and regional recurrence rates were $10.3 \%$ (6/58 patients) and 15.5\% (9/58 patients), respectively, in this study involving 58 patients with T1-2N0 OTSCC. The survival rate of patients with local recurrence was $66.7 \%$, which was significantly lower than that (96.2\%) of patients without local recurrence, whereas the survival rate of patients with regional recurrence was $85.5 \%$, which was not significantly difference from that (96.2\%) of patients without regional recurrence. The outcome became unfavorable once local recurrence occurred, re-confirming the importance of the first treatment. POI, NAC and the status of the surgical margin were identified as factors influencing local recurrence. In particular, the status of the deep surgical margin was a high 
potential independent risk factor. The deep surgical margin was resected closely in many NAC-treated cases, suggesting that NAC may lead to local recurrence and poor outcomes. No efficacy of NAC was observed, suggesting that the standard treatment of T1-2N0 OTSCC is surgery alone, and when local recurrence occurs, salvage surgery should be performed, if resectable. Moreover, our results did not indicate any advantage of elective neck dissection for the treatment of N0 neck in early OTSCC.

\section{References}

1. Jemal A, Bray F, Center MM, Ferlay J, Ward E, Forman D (2011) Global Cancer Statistics 2011. CA Cancer J Clin 61: 69-90

2. Warnakulasuriya S (2009) Global epidemiology of oral and oropharyngeal cancer. Oral Oncol 45: 309-316

3. National Cancer Institute (2012). Surveillance, Epidemiology, and End Results (SEER) web site. http://seer.cancer.gov/statistics/. Accessed 15 March 2012

4. Rusthoven KE, Raben D, Song JI, Kane M, Altoos TA, Chen C (2010) Survival and patterns of relapse in patients with oral tongue cancer. J Oral Maxillofac Surg 68: 584-589

5. Ganly I, Patel S, Shah J (2012) Early stage squamous cell cancer of the oral tongue-clinicopathologic features affecting outcome. Cancer 118: 101-111

6. Spiro RH, Guillamondegui O, Paulino AF, Huvos AG (1999) Pattern of invasion and margin assessment in patients with oral tongue cancer. Head Neck 21: $408-413$

7. Goto M, Hasegawa Y, Terada A, Hyodo I, Hanai N, Ijichi K, Yamada H, Fujimoto Y, Ogawa T (2005) Prognostic significance of late cervical 
metastasis and distant failure in patients with stage I and II oral tongue cancers. Oral Oncol 41: 62-69

8. Brandwein-Gensler M, Teixeira MS, Lewis CM, Lee B, Rolnitzky L, Hille JJ, Genden E, Urken ML, Wang BY (2005) Oral squamous cell carcinoma. Histologic risk assessment, but not margin status, is strongly predictive of local disease-free and overall survival. Am J Surg Pathol 29: 167-178

9. Pentenero M, Gandolfo S, Carrozzo M (2005) Importance of tumor thickness and depth of invasion in nodal involvement and prognosis of oral squamous cell carcinoma a review of the literature. Head Neck 27: 1080-1091

10. Vered M, Dayan D, Dobriyan A, Yahalom R, Shalmon B, Barshack I, Bedrin L, Talmi YP, Taicher S (2010) Oral tongue squamous cell carcinoma: recurrent disease is associated with histopathologic risk score and young age. J Cancer Res Clin Oncol 136: 1039-1048

11. El-Naaj IA, Leiser Y, SHveis M, Sabo E, Peled M (2011) Incidence of oral cancer occult metastasis and survival of T1-T2N0 oral cancer patients. J Oral Maxillofac Surg 69: 2674-2679

12. Shah JP, Gil Z (2009) Current concepts in management of oral cancer. Oral Oncol 45: 394-401

13. Brennan S, Corry J, Kleid S, Porceddu S, Yuen K, Rischin D, Peters LJ (2010) Prospective trial to evaluate staged neck dissection or elective neck radiotherapy in patients with ct-staged T1-2 N0 squamous cell carcinoma of the oral tongue. Head Neck 32: 191-198

14. Nag S, Cano ER, Demanes J, Puthawala AA, Vikram B (2001) The American brachytherapy society recommendations for high-dose-rate brachytherapy for head-and-neck carcinoma. Int J Radia Oncol Biol Phys 50: 1190-1198 
15. Mazeron JJ, Ardiet JM, Haie-Meder C, Kovacs G, Levendag P, Peiffert D, Polo A, Rovirosa A, Strnad V (2009) GEC-ESTRO recommendations for brachytherapy for head and neck squamous cell carcinomas. Radiother Oncol 91: $150-156$

16. Umeda M, Komatsubara H, Ojima Y, Minamikawa T, Shibuya Y, Yokoo , Ishii J, Komori T (2005) A comparison of brachytherapy and surgery for the treatment of stage I - II squamous cell carcinoma of the tongue. Int J Oral Maxillofac Surg 34: 739-744

17. Sobin LH, Wittekind C (2002) UICC TNM classification of malignant tumours. 6th ed. Wiley \& Sons, New York

18. Pindborg JJ, Reichart PA, Smith CJ, van der Waal I, ed. (1997) World Health Organization Histological Typing of Cancer and Precancer of the Oral Mucosa. 2nd ed. Springer, New York

19. Bryne M, Boysen M, Alfsen CG, Abeler VM, Sudbø J, Nesland JM, Kristensen GB, Piffko J, Bankfalvi A (1998) The invasive front of carcinomas. The most important area for tumor prognosis? Anticancer Res 18: $4757-4764$

20. Asakage T, Yokose T, Mukai K, Tsugane S, Tsubono Y, Asai M, Ebihara S (1998) Tumor thickness predicts cervical metastasis in patients with stage I / II carcinoma of the tongue. Cancer 82: 1443-1448

21. Kurokawa H, Yamashita Y, Takeda S, Zhang M, Fukuyama H, Takahashi T (2002) Risk factors for late cervical lymph node metastases in patients with stage I or II carcinoma of the tongue. Head Neck 24: 731-736

22. Lim SC, Zhang S, Ishii G, Endoh Y, Kodama K, Miyamoto S Hayashi R, Ebihara S, Cho JS, Ochiai A (2004) Predictive markers for late cervical 
metastasis in stage I and II invasive squamous cell carcinoma of the oral tongue. Clin Cancer Res 10: 166-172

23. Sparano A, Weinstein G, Chalian A, Yodul M, Weber R (2004) Multivariate predictors of occult neck metastasis in early oral tongue cancer. Otolaryngol Head Neck Surg 131: 472-476

24. Huang SH, Hwang D, Lockwood G, Goldstein DP, O’Sullivan B (2009) Predictive value of tumor thickness for cervical lymph-node involvement in squamous cell carcinoma of the oral cavity. A meta-analysis of reported studies. Cancer 115: 1489-1497

25. Fan KH, Wang HM, Kang CJ, Lee LY, Huang SF, Lin CY, Chen EYC, Chen IH, Liao CT, Chang JTC (2010) Treatment results of postoperative radiotherapy on squamous cell carcinoma of the oral cavity: coexistence of multiple minor risk factors results in higher recurrence rates. Int J Radiation Oncology Biol Phys 77: 1024-1029

26. Kernohan MD, Clark JR, Gao K, Ebrahimi A, Milross CG (2010) Predicting the prognosis of oral squamous cell carcinoma after first recurrence. Arch Otolaryngol Head Neck Surg 136: 1235-1239

27. Huang TY, Hsu LP, Wen YH, Huang TT, Chou YF, Lee CF, Yang MC, Chang YK, Chen PR (2010) Predictors of locoregional recurrence in early stage oral cavity cancer with free surgical margins. Oral Oncol 45: 49-55

28. O-charoenrat PO, Pillai G, Patel S, Fisher C, Archer D, Eccles S, Rhys-Evans P (2003) Tumour thickness predicts cervical nodal metastases and survival in early oral tongue cancer. Oral Oncol 39: 386-390

29. Al-Rajhi N, Khafaga Y, El-Husseiny J, Saleem M, Mourad W, Al-Otieschan A, Al-Amro A (2000) Early stage carcinoma of oral tongue: prognostic factors for local control and survival. Oral Oncol 36: 508-514 
30. Yuen APW, Lam KY, Lam LK, Ho CM, Wong A, Chow TL, Yuen WF, Wei WI (2002) Prognostic factors of clinically stage I and II oral tongue carcinoma-a comparative study of stage, thickness, shape, growth pattern, invasive front malignancy grading, Martines-Gimen score, and pathologic features. Head Neck 24: 513-520

31. Keski-Säntti H, Atula T, Tikka J, Hollmén J, Mäkitie AA, Leivo I (2007) Predictive value of histopathologic parameters in early squamous cell carcinoma of oral tongue. Oral Oncol 43: 1007-1013

32. Pignon JP, Bourhis J, Domenge C, Designe L (2000) Chemotherapy added to locoregional treatment for head and neck squamous-cell carcinoma: three meta-analyses of updated individual data. Lancet 355: 949-955

33. Kirita T, Ohgi K, Kawakami M, Miyawaki S, Okamoto M, Yamanaka Y, Sugimura M (2002) Primary tumour resection of tongue carcinoma based on response to preoperative therapy. Int J Oral Maxillofac Surg 31: 267-272

34. Licitra L, Grandi C, Guzzo M, Mariani L, Lo Vullo S, Valvo F, Quattrone P, Valagussa P, Bonadonna G, Molinari R, Cantu G (2003) Primary chemotherapy in resectable oral cavity squamous cell cancer: a randomized controlled trial. J Clin Oncol 21: 327-333

35. Olasz L, Szalma J, Orsi E, Tornoczky T, Marko T, Nyarady Z (2010) Neoadjuvant chemotherapy: Does it have benefits for surgeon in the treatment of advanced squamous cell cancer of the oral cavity? Pathol Oncol Res 16: 207-212

36. Lore JM, Diaz-Ordaz E, Spaulding M, Chary K, Kaufman S, Lawrence W, Hong F, Gerold T, Sundquist N, Barrali RA (1995) Improved survival with preoperative chemotherapy followed by tumor response for advanced squamous cell carcinoma of the head and neck. Am J Surg 170: 506-511 
37. Okura M, Hiranuma T, Adachi T, Ogura T, Aikawa T, Yoshioka H, Hayashido Y, Kogo M, Matsuya T (1998) Induction chemotherapy is associated with an increase in the incidence of locoregional recurrence in patients with carcinoma of the oral cavity: results from a single institution. Cancer 82: 804-815

38. Bernier J, Domenge C, Ozsahin M, Matuszewska K, Lefebvre JL, Greiner RH, Giralt J, Maingon P, Rolland F, Michel B, Cognetti F, Bourhis J, Kirkpatrick A, van Glabbeke M (2004) Postoperative irradiation with or without concomitant chemotherapy for locally advanced head and neck cancer. N Eng J Med 350: 1945-1952

39. Kurita H, Nakanishi Y, Nishizawa R, Xiao T, Kamata T, Koike T, Kobayashi $\mathrm{H}$ (2010) Impact of different surgical margin conditions on local recurrence of oral squamous cell carcinoma. Oral Oncol 46: 814-817

40. Sutton DN, Brown JS, Rogers SN, Vaughan ED, Woolgar JA (2003) The prognostic implications of the surgical margin in oral squamous cell carcinoma. Int J Oral Maxillofac Surg 32: 30-34

41. Upile T, Fisher C, Jerjes W, El Maaytah M, Searle A, Archer D, Michaels, L, Rhys-Evans P, Hopper C, Howard D, Wright A (2007) The uncertainty of the surgical margin in the treatment of head and neck cancer. Oral Oncol 43: 321326

42. Umeda M, Shigeta T, Takahashi H, Minamikawa T, Komatsubara H, Oguni A, Shibuya Y, Komori T (2011) Cinical evaluation of Lugol's iodine staining in the treatment of stage I - II squamous cell carcinoma of the tongue. Int J Oral Maxillofac Surg 40: 593-596

43. Kim jj, Tannock IF (2005) Repopulation of cancer cells during therapy: an important cause of treatment failure. Nat Rev Cancer 5: 516-525 
44. Bourhis J, Wilson G, Wibault P, Janot F, Bosq J, Armand JP, Luboinski B, Malaise EP, Eschwege F (1994) Rapid tumor cell proliferation after induction chemotherapy in oropharyngeal cancer. Laryngoscope 104: 468-472

45. Penel N, Fournier C, Lefebvre D, Roussel-Delvallez M, Sarini J, Kar A, Mallet Y, Lefebvre JL (2004) Previous chemotherapy as a predictor of wound infections in nonmajor head and neck surgery: results of a prospective study. Head Neck 26: 513-517

46. Penel N, Fournier C, Lefebvre D, Lefebvre JL (2005) Multivariate analysis of risk factors for wound infection in head and neck squamous cell carcinoma surgery with opening of mucosa. Study of 260 surgical procedures. Oral Oncol 41: 294-303

47. Rahima B, Shingaki S, Nagata M, Saito C (2004) Prognostic significance of perineural invasion in oral and oropharyngeal carcinoma. Oral Surg Oral Med Oral Pathol Oral Radiol Endod 97: 423-431

48. Gonzalez-Garcia R, Naval-Gias L, Roman-Romero L, Sastre-Perez J, Rodriguez-Campo FJ (2009) Local recurrences and second primary tumors from squamous cell carcinoma of the oral cavity: a retrospective analytic study of 500 patients. Head Neck 31: 1168-1180

49. Ord RA, Kolokythas A, Reynolds MA (2006) Surgical salvage for local and regional recurrence in oral cancer. J Oral Maxillofac Surg 64: 1409-1414

50. Schwartz GJ, Mehta RH, Wenig BL, Shaligram C, Portugal LG (2000) Salvage treatment for recurrent squamous cell carcinoma of the oral cavity. Head Neck 22: 34-41

51. Sklenicka S, Gardiner S, Dierks EJ, Potter BE, Bell RB (2010) Survival analysis and risk factors for recurrence in oral squamous cell carcinoma: Does surgical salvage affect outcome? J Oral Maxillofac Surg 68: 1270-1275 
52. Kaya S, Yilmaz T, Gürsel B, Saraç S, Sennaroğlu L (2001) The value of elective neck dissection in treatment of cancer of the tongue. Am J Otolaryngol 22: 59-64

53. Lim YC, Lee JS, Koo BS, Kim SH, Kim YH, Choi EC (2006) Treatment of contralateral N0 neck in early squamous cell carcinoma of the oral tongue: elective neck dissection versus observation. Laryngoscope 116: 461-465 


\section{Figure Legend}

Fig 1 Disease-specific survival (DSS) and recurrence-free survival (RFS) curves by the KaplanMeier method.

Fig 2 Disease-specific survival (DSS) for local recurrence.

Fig 3 Disease-specific survival (DSS) for regional recurrence. 
Fig 1

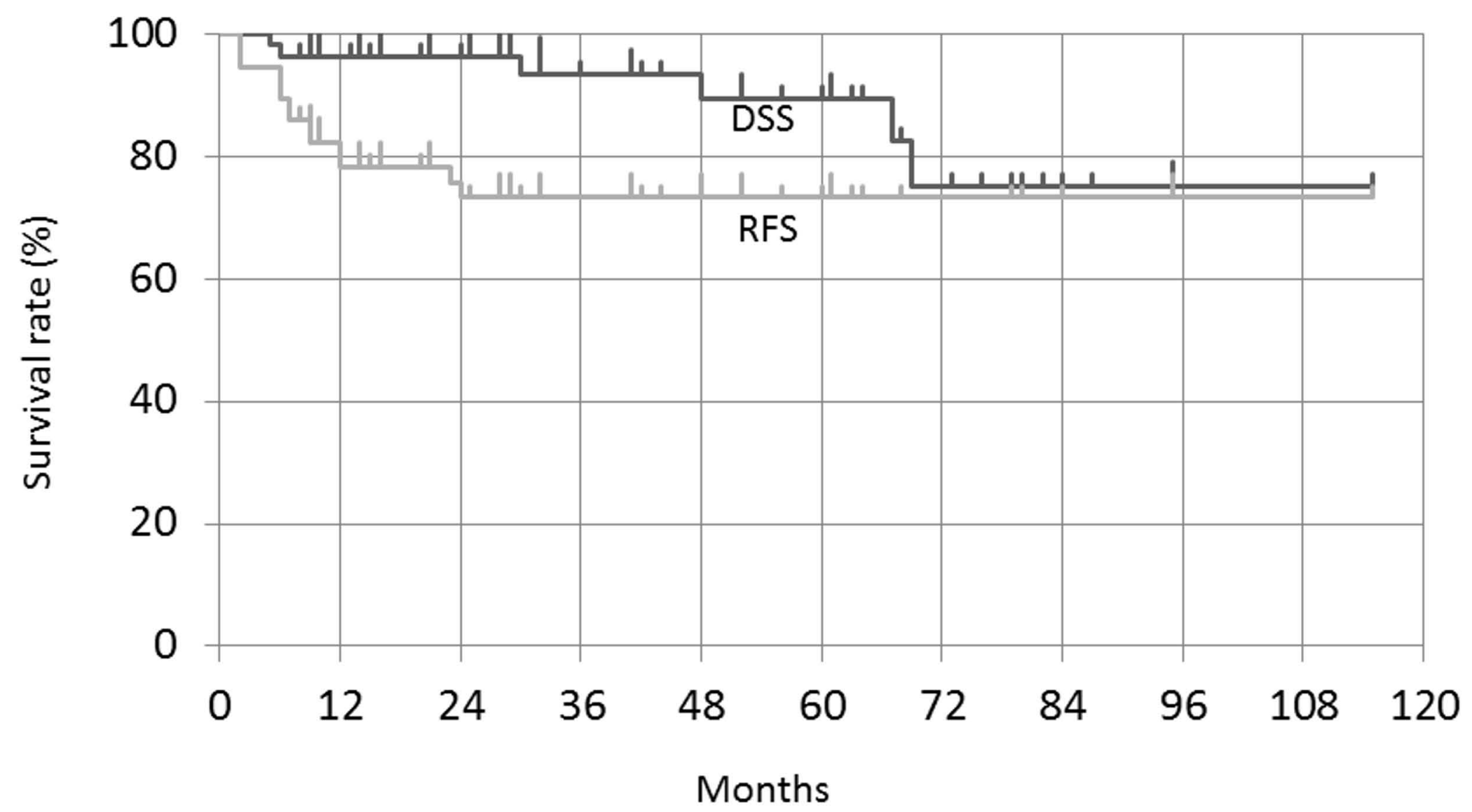


Fig 2

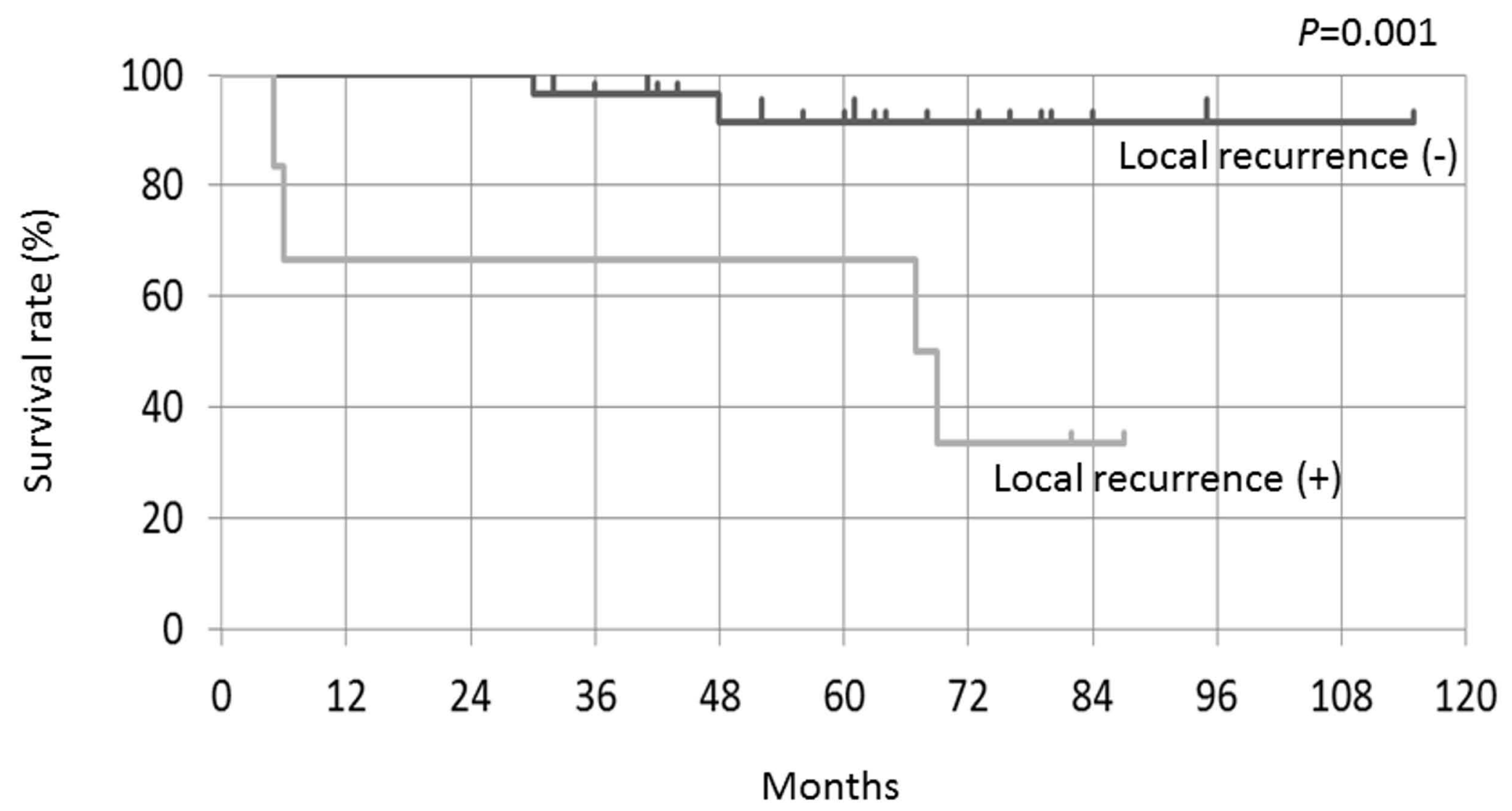


Fig 3

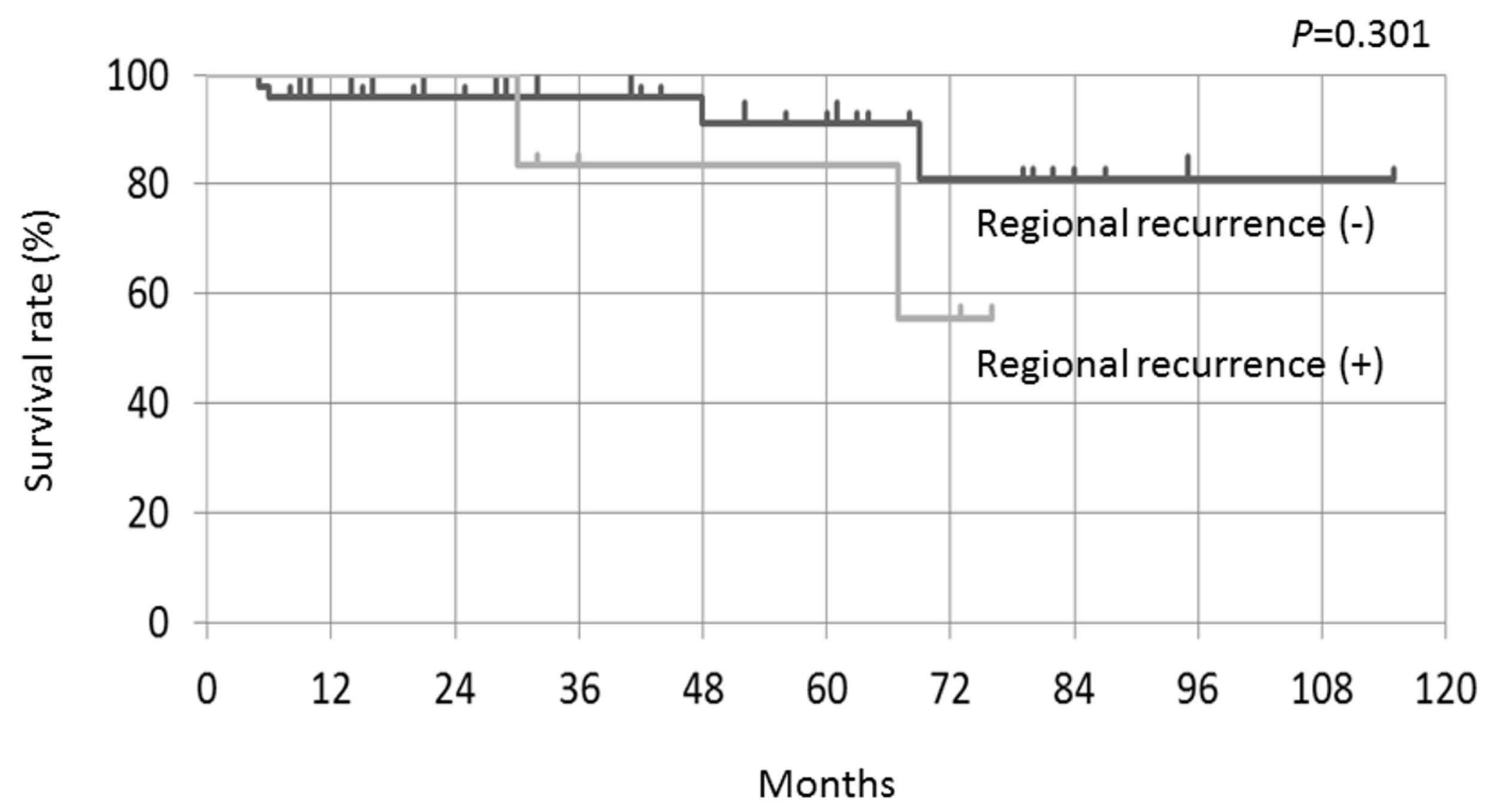


Table 1 Demographic characteristics of 58 patients with T1-2N0 oral tongue squamous cell carcinoma

\begin{tabular}{|c|c|}
\hline Characteristics & No. of cases (\%) \\
\hline \multicolumn{2}{|l|}{ Gender } \\
\hline Male & $31(53.4)$ \\
\hline Female & $27(46.6)$ \\
\hline \multicolumn{2}{|l|}{ Age } \\
\hline$\geq 66$ & 33 (56.9) \\
\hline$\leq 65$ & $25(43.1)$ \\
\hline \multicolumn{2}{|l|}{ T stage } \\
\hline $\mathrm{T} 1$ & $27(46.6)$ \\
\hline $\mathrm{T} 2$ & $31(53.4)$ \\
\hline \multicolumn{2}{|l|}{ Histological grade } \\
\hline Well & $53(91.4)$ \\
\hline Moderately & $4(6.9)$ \\
\hline Poorly & $1(1.7)$ \\
\hline \multicolumn{2}{|l|}{ POI } \\
\hline 1 & $5(8.6)$ \\
\hline 2 & $12(20.7)$ \\
\hline 3 & 35 (60.3) \\
\hline 4 & $6(10.4)$ \\
\hline \multicolumn{2}{|l|}{ Treatment } \\
\hline Surgery alone & $44(75.9)$ \\
\hline NAC + surgery & $14(24.1)$ \\
\hline \multicolumn{2}{|l|}{ DOI } \\
\hline$<4 \mathrm{~mm}$ & $42(72.4)$ \\
\hline$\geq 4 \mathrm{~mm}$ & $16(27.6)$ \\
\hline \multicolumn{2}{|c|}{ Superficial surgical margin } \\
\hline$>4 \mathrm{~mm}$ & $47(81.0)$ \\
\hline$\leq 4 \mathrm{~mm}$ & $11(19.0)$ \\
\hline \multicolumn{2}{|c|}{ Deep surgical margin } \\
\hline$>4 \mathrm{~mm}$ & $53(91.4)$ \\
\hline$\leq 4 \mathrm{~mm}$ & $5(8.6)$ \\
\hline
\end{tabular}


Table 1 (Continued)

\begin{tabular}{lc}
\hline Characteristics & No. of cases (\%) \\
\hline Perineural invasion & \\
No & $44(75.9)$ \\
Yes & $14(24.1)$ \\
Recurrence & \\
No & $43(74.1)$ \\
Local & $6(10.3)$ \\
Regional & $9(15.5)$ \\
\hline
\end{tabular}

POI: pattern of invasion; NAC: neoadjuvant chemotherapy; DOI: depth of invasion. 
Table 2 Univariate analysis for the factors influencing locoregional recurrence and survival rates of 58 patients with T1-2N0 oral tongue squamous cell carcinoma

\begin{tabular}{|c|c|c|c|c|c|c|c|c|c|c|}
\hline Factor & $\begin{array}{c}\text { No. of LR } \\
\text { (\%) }\end{array}$ & $P$ & $\begin{array}{c}\text { No. of RR } \\
\text { (\%) }\end{array}$ & $P$ & $\begin{array}{c}\text { No. of LRR } \\
\text { (\%) }\end{array}$ & $P$ & $\begin{array}{r}\text { DSS } \\
(\%)\end{array}$ & $P$ & $\begin{array}{r}\text { RFS } \\
(\%)\end{array}$ & $P$ \\
\hline Gender & & 0.482 & & 0.697 & & 0.892 & & 0.405 & & 0.949 \\
\hline Male & 2/32 (6.3) & & 6/32 (12.8) & & 8/32 (25.0) & & 84.3 & & 74.9 & \\
\hline Female & 4/26 (15.4) & & 3/26 (11.5) & & 7/26 (26.9) & & 96.3 & & 72.4 & \\
\hline Age & & 0.940 & & 0.649 & & 0.531 & & 0.738 & & 0.236 \\
\hline$\geq 66$ & 3/33 (9.1) & & 4/33 (12.1) & & 7/33 (21.2) & & 85.5 & & 80.7 & \\
\hline$\leq 65$ & 3/25 (12.0) & & $5 / 25(20.0)$ & & 8/25 (32.0) & & 96.0 & & 61.7 & \\
\hline T stage & & 0.800 & & 0.219 & & 0.136 & & 0.487 & & 0.186 \\
\hline $\mathrm{T} 1$ & $2 / 27(7.4)$ & & $2 / 27(7.4)$ & & 4/27 (14.8) & & 100 & & 80.9 & \\
\hline $\mathrm{T} 2$ & 4/31 (12.9) & & 7/31 (22.6) & & 11/31 (35.5) & & 84.5 & & 66.7 & \\
\hline Histological grade & & 0.131 & & 0.026 & & $<0.001$ & & 0.108 & & $<0.001$ \\
\hline Well & 4/53 (7.5) & & 6/53 (11.3) & & 10/53 (18.9) & & 91.6 & & 82.3 & \\
\hline Moderately + Poorly & $2 / 5(40.0)$ & & $3 / 5(60.0)$ & & $5 / 5(100)$ & & 75.0 & & 0 & \\
\hline POI & & 0.008 & & 0.608 & & 0.055 & & $<0.001$ & & 0.010 \\
\hline $1+2+3$ & 3/52 (5.8) & & 8/52 (15.4) & & $11 / 52(21.2)$ & & 95.0 & & 79.0 & \\
\hline 4 & $3 / 6(50.0)$ & & 1/6 (16.7) & & $4 / 6(66.7)$ & & 33.3 & & 33.3 & \\
\hline Treatment & & 0.039 & & 0.261 & & 0.007 & & $<0.001$ & & 0.011 \\
\hline Surgery alone & $2 / 44(4.5)$ & & 5/44 (11.4) & & 7/44 (15.9) & & 95.7 & & 81.6 & \\
\hline NAC + surgery & 4/14 (28.6) & & 4/14 (28.6) & & 8/14 (57.1) & & 76.2 & & 49.0 & \\
\hline
\end{tabular}


Table 2 (Continued)

\begin{tabular}{|c|c|c|c|c|c|c|c|c|c|c|}
\hline Factor & $\begin{array}{c}\text { No. of LR } \\
\text { (\%) }\end{array}$ & $P$ & $\begin{array}{c}\text { No. of RR } \\
\text { (\%) }\end{array}$ & $P$ & $\begin{array}{c}\text { No. of LRR } \\
(\%)\end{array}$ & $P$ & $\begin{array}{r}\text { DSS } \\
(\%)\end{array}$ & $P$ & $\begin{array}{r}\text { RFS } \\
(\%)\end{array}$ & $P$ \\
\hline DOI & & 0.415 & & 0.102 & & 0.024 & & 0.013 & & 0.026 \\
\hline$<4 \mathrm{~mm}$ & $3 / 42(7.1)$ & & 4/42 (9.59 & & $7 / 42(16.7)$ & & 100 & & 79.7 & \\
\hline$\geq 4 \mathrm{~mm}$ & 3/16 (18.8) & & $5 / 16(31.3)$ & & $8 / 16(50.0)$ & & 70.7 & & 55.6 & \\
\hline Superficial surgical margin & & $<0.001$ & & 0.463 & & $<0.001$ & & 0.253 & & $<0.001$ \\
\hline$>4 \mathrm{~mm}$ & $1 / 47(2.1)$ & & 6/47 (12.8) & & 7/47 (14.9) & & 88.7 & & 84.0 & \\
\hline$\leq 4 \mathrm{~mm}$ & $5 / 11(45.5)$ & & 3/11 (27.3) & & $8 / 11(72.7)$ & & 75.8 & & 32.7 & \\
\hline Deep surgical margin & & 0.002 & & 0.723 & & 0.018 & & 0.002 & & 0.037 \\
\hline$>4 \mathrm{~mm}$ & $3 / 53(5.7)$ & & $8 / 53(15.1)$ & & $11 / 53(20.8)$ & & 90.1 & & 77.4 & \\
\hline$\leq 4 \mathrm{~mm}$ & $3 / 5(60.0)$ & & $1 / 5(20.0)$ & & $4 / 5(80.0)$ & & 80.0 & & 30.0 & \\
\hline Perineural invasion & & 0.039 & & 0.781 & & 0.044 & & $<0.001$ & & 0.052 \\
\hline No & $2 / 44(4.5)$ & & 6/44 (13.6) & & 8/44 (18.2) & & 100 & & 79.8 & \\
\hline Yes & 4/14 (28.6) & & $3 / 14$ (21.4) & & $7 / 14(50.0)$ & & 64.3 & & 53.6 & \\
\hline
\end{tabular}

LR: local recurrence; RR: regional recurrence; LRR: locoregional recurrence; DSS: disease-specific survival; RFS: recurrence-free survival; POI: pattern of invasion; NAC: neoadjuvant chemotherapy; DOI: depth of invasion 
Table 3 Multivariate regression analysis of the factors influencing locoregional recurrence and survival rates of 58 patients with T1-2N0 oral tongue squamous cell carcinoma

\begin{tabular}{|c|c|c|c|c|c|}
\hline Factor & $\begin{array}{c}\text { LR } \\
\text { HR (95\% CI) }\end{array}$ & $\begin{array}{c}\text { RR } \\
\text { HR (95\% CI) }\end{array}$ & $\begin{array}{c}\text { LRR } \\
\text { HR (95\% CI) }\end{array}$ & $\begin{array}{c}\text { DSS } \\
\text { HR (95\% CI) }\end{array}$ & $\begin{array}{c}\text { RFS } \\
\text { HR (95\% CI) }\end{array}$ \\
\hline POI & $P=0.137$ & $P=0.379$ & $P=0.264$ & $P=0.044$ & $P=0.101$ \\
\hline $1+2+3$ & 1 & 1 & 1 & 1 & 1 \\
\hline 4 & $10.67(0.47-242.63)$ & 0.38 (0.03-4.67) & $3.40(0.40-29.02)$ & 12.49 (1.06-12.49) & $2.92(0.81-10.48)$ \\
\hline Treatment & $P=0.262$ & $P=0.649$ & $P=0.247$ & $P=0.736$ & $P=0.171$ \\
\hline Surgery alone & 1 & 1 & 1 & 1 & 1 \\
\hline NAC + surgery & $4.72(0.31-70.95)$ & $1.56(0.23-10.61)$ & $2.70(0.50-14.50)$ & 1.78 (0.06-51.38) & $2.76(0.65-11.78)$ \\
\hline DOI & $P=0.666$ & $P=0.130$ & $P=0.593$ & $P=0.269$ & $P=0.486$ \\
\hline$<4 \mathrm{~mm}$ & 1 & 1 & 1 & 1 & 1 \\
\hline$\geq 4 \mathrm{~mm}$ & $0.49(0.02-12.46)$ & $4.27(0.65-27.91)$ & $1.61(0.28-9.26)$ & $3.70(0.36-37.71)$ & $1.60(0.42-6.07)$ \\
\hline Deep surgical margin & $P=0.039$ & $P=0.862$ & $P=0.324$ & $P=0.041$ & $P=0.007$ \\
\hline$>4 \mathrm{~mm}$ & 1 & 1 & 1 & 1 & 1 \\
\hline$\leq 4 \mathrm{~mm}$ & $14.83(1.15-190.80)$ & $1.26(0.09-17.09)$ & 3.07 (0.33-28.53) & 21.13 (1.14-391.88) & $7.15(1.69-30.24)$ \\
\hline
\end{tabular}

LR: local recurrence; RR: regional recurrence; LRR: locoregional recurrence; DSS: disease-specific survival; RFS: recurrence-free survival; HR: hazard ratio; CI: confidence interval; POI: pattern of invasion; NAC: neoadjuvant chemotherapy; DOI: depth of invasion 
Table 4 Effect of POI, NAC, and DOI on the deep margin status

\begin{tabular}{lccc}
\hline Variable & HR & 95\%CI & $P$ value \\
\hline Deep margin status $(\leq 4 \mathrm{~mm})$ & 1 & & \\
POI type $1+2+3$ & 16.58 & $2.02-136.13$ & 0.009 \\
POI type 4 & & & \\
Deep margin status $(\leq 4 \mathrm{~mm})$ & 1 & & 0.002 \\
$\quad$ Surgery alone & 13.34 & $2.58-69.01$ & \\
NAC & & & \\
Deep margin status $(\leq 4 \mathrm{~mm})$ & 1 & & 0.521 \\
DOI $<4$ mm & 1.86 & $0.28-12.30$ & \\
DOI $\geq 4$ mm &
\end{tabular}

POI: pattern of invasion; NAC: neoadjuvant chemotherapy; DOI: depth of invasion; HR: hazard ratio; CI: confidence interval 